Send your letters to the Editor,

British Dental Journal,

64 Wimpole Street

London

W1G 8YS

Email bdj@bda.org

Priority will be given to letters less than 500 words long.

Authors must sign the letter, which

may be edited for reasons of space.

\section{THE SAME MISTAKES}

Sir, opening further colleges and training more oral health care providers is the current practice to try and overcome the enormous and widening disparities in access to quality care within developing countries, especially in rural areas, but is it the correct course? In countries like Brazil and others, this practice has been disastrous with an insignificant improvement in oral health of the population and a growing dissatisfaction among those so trained due to few job opportunities leading to a search for other occupations, and also to closure of dental schools.

India is passing through the same stage and perpetrating the same mistakes. Fresh dental graduates are paid less then Rs 6,000 per month (approximately US\$120), with many dental graduates forced to work in call centres or to change profession. Increasing the number of health professionals is not going to help the problem and will lead to tarnishing the profession.

Numerous dental colleges in India lack basic equipment and materials and are in such a bad condition that patients are being referred from them to dental clinics. Many such schools, admitting 100 students per year, have an out-patient department of less then two patients a day, but fake entries are added to the register to be shown at the time of college inspection. The students are being sold the degree, examination results are being manipulated and students who have never attended the college are being awarded degrees. The message is clear, 'pay the fees and get the degree'. The quality of dentists being produced in these schools is below satisfactory.

These schools have acute shortages of both teaching and non-teaching staff, with one BDS trained staff member running two or three departments and MDS staff are 'on paper' only, just for the inspections. College management recruit teaching staff of other colleges such as nursing or MBA, and non-teaching staff, to imitate doctors and patients. Many of them are caught red-handed but then nothing happens. There are many such schools running throughout the country.

The problem has gone much beyond the limits but can be dealt with if the dental council, government, and health professionals join hands. The dental council should hold regular inspections of the colleges and those lacking minimum standard criteria should be warned and if required, closed. Strict action should be taken against corrupt officers. Health professionals should not just be a witness to these acts. They should raise their voice in public even if the council is not willing to listen to such colleges. The government must understand its duty towards its people and act accordingly. No new dental colleges should be allowed to open for a period of a few years, and a minimum salary should be fixed for the graduate by the government. If the oral health of the community and the dignity of the dental profession are to be maintained then there are questions which we as health care professionals have to think about and answer.

$$
\begin{array}{r}
\text { A. Singh, Bhopal } \\
\text { DOI: } 10.1038 / \text { sj.bdj.2010.297 }
\end{array}
$$

\section{$\mathrm{H}_{2} \mathrm{O}_{2}$ AND THE LAW}

Sir, I read with interest the article entitled Clinical use of hydrogen peroxide in surgery and dentistry - why is there a safety issue? by Patel, Kelleher and McGurk (BDJ 2010; 208: 61-64). It is clear from the cases presented that dilute hydrogen peroxide solution is of very great value in the surgical management of head and neck oncology where complications can be grave indeed.

However, I did notice an incorrect statement in relation to the UK law in respect of the sale and supply of solutions containing $>0.1 \%$ hydrogen peroxide. The current version of the Cosmetic Products (Safety) Regulations (CPSR) ${ }^{1}$ restricts the concentration of hydrogen peroxide present or released by 'oral hygiene products' to a maximum of $0.1 \%$. Skin-care preparations may contain or release up to $4 \%$ and hair-care preparations up to $12 \%$ hydrogen peroxide. Unfortunately, following the House of Lords judgement in Optident Limited and Another $v$. Secretary of State For Trade and Industry and Another, ${ }^{2}$ it is clear that products for tooth whitening are classed as cosmetics within the meaning of the EU Cosmetics Directive ${ }^{3}$ (and thus the UK conformative legislation), and hence subject to the $0.1 \%$ maximum hydrogen peroxide limit.

The definition of 'supply' in the context of in-surgery tooth whitening does not yet appear to have been tested in the UK courts. Whatever arguments may be advanced in this respect, it does seem clear that providing a patient with a tooth whitening product for home use would constitute 'supply', and therefore fall within the ambit of the CPSR.

Consumer safety law is concerned with protection of consumers in the widest possible sense. Although the point is well made in this article that dilute hydrogen peroxide is safe for use on delicate soft tissues, it does not necessarily follow that it is safe for consumers to have unsupervised access to significantly higher concentrations of 
hydrogen peroxide. Amendment of the current law to differentiate between 'general' supply, and 'professional use' would be of considerable assistance to dentists when the option of bleaching might obviate a destructive alternative such as veneer or crown preparation.

It should be borne in mind, however, that the SCCP 2007 report $^{4}$ which is often quoted as supporting an increase in the permitted concentration of hydrogen peroxide to $6 \%$ in cosmetics supplied for tooth whitening purposes does not, in fact, confirm that any concentration greater than $0.1 \%$ is safe for use over long periods, highlighting a need for additional research. If in the future it were to be discovered, for instance, that the long-term use of products containing $0.1-6 \%$ hydrogen peroxide had a significant mutagenic effect, the existence of doubt as to safety raised by the SCCP report could render many suppliers, including dentists, vulnerable to claims that this should have been recognised.

I do question the inclusion of the "in brief' practice point inserted at the head of the article stating that 'The dental profession should consider hydrogen peroxide more often in clinical use'. I do not believe the current article states or supports this point, or even that it set out to do so.

\section{H. Beckett, Waterlooville}

1. S.I. 20081284

2. [2001] UKHL 32

3. Council Directive $76 / 768 /$ EEC, as amended by 93/35/EEC.

4. Scientific Committee on Consumer Products. Opinion on Hydrogen peroxide, in its free form or when released, in oral hygiene products and tooth whitening products. SCCP/1129/07.

DOI: 10.1038/sj.bdj.2010.298

\section{DIFFERING GUIDELINES}

Sir, I enjoyed reading the paper Antibiotic prophylaxis in oral health care - the agreement between Swedish recommendations and evidence (BDJ 2010; 208: E5). It is a good illustration that guidelines concerning this issue have not always been recently reviewed in all countries, and are not the same throughout the world. It serves as a reminder to dental practitioners moving to new jurisdictions outside of the United Kingdom that they need to be aware of local guidelines which may be different to those they have used here. In the United States of America, interpre- tation of the same evidence as that considered by NICE has resulted in slightly different guidelines as to the need for antibiotics prophylaxis. ${ }^{1}$ The American Heart Association guidelines are influential throughout the world and whilst many countries are now producing less interventional guidelines than previously, many still recommend antibiotic prophylaxis in limited indications, especially where the underlying cardiac condition is associated with the highest risk of adverse outcome from infective endocarditis. ${ }^{2,3}$

\section{Pemberton, Manchester}

1. Wilson W, Taubert K A, Gewitz M et al. Prevention of infective endocarditis: guidelines from the American Heart Association. J Am Dent Assoc 2007; 138: 739-760.

2. Daly C G, Currie B J, Jeyasingham M S et al. A change of heart: the new infective endocarditis prophylaxis guidelines. Aust Dent J 2008; 53: 196-200.

3. Delahaye F, Harbaoui B, Cart-Regal V et al. Recom mendations on prophylaxis for infective endocarditis: Dramatic changes over the past seven years. Arch Cardiovasc Dis 2009; 102: 233-245.

DOI: 10.1038/sj.bdj.2010.299

\section{OIL IN CHEEK}

Sir, I was fascinated to read the recent letters in the $B D J$ regarding 'oil pulling' - the process of using cooking oil as a mouthwash, its efficacy apparently proved by the way the oil takes on a milky colour after a few minutes of vigorous swishing. However, it has occurred to me that we are already familiar with a similar process used for many years albeit on an industrial scale rather than intra-orally. We substitute the oil with milk, the process is called churning, and the net result is butter. Just to clarify (pun intended), according to Wikipedia the change of colour is due to the transforming of a fat-in-water emulsion (milk) to a water-in-fat emulsion (butter) rather than any magical healing properties. As regards the research that was reported in one of the letters, the oil was only compared with water, so it could well be that other viscous liquids may give a similar improvement - may I suggest jelly and ice cream as a possibility for further research? (sugar free of course).

R. Nute, Swansea

DOI: 10.1038/sj.bdj.2010.300

\section{INTUBATION LITIGATION}

Sir, I was recently asked to see a patient by one of our anaesthetic colleagues. The patient was coming round from a general anaesthetic when the anaesthetist noticed some bleeding around the gingival margin of tooth 11 and was concerned by this appearance.

When I examined the patient that afternoon there was evident periodontal disease with 11 exhibiting grade III mobility. The patient also mentioned that the tooth in question had been sore since he woke up from the general anaesthetic.

Obviously, it was difficult to ascertain if the mobility was caused by the anaesthetist when extubating or whether the mobility was prevalent pre-operatively due to periodontal breakdown.

Recently, I read a statement by the MDU that mentioned over half the claims against anaesthetists were dental damage mainly caused by a laryngoscope. The risks are greater on a tooth with poor prognosis and these should be identified at the anaesthetic assessment and be part of the consenting procedure. The statement went on to mention that damage could occur not solely from difficult intubation but from patients biting onto the endo-tracheal tube or similar devices.

I wonder whether increased training for our medical counterparts is required or an increased awareness for such issues to reduce the litigations in this field.

Z. Esmail, Newcastle DOI: 10.1038/sj.bdj.2010.301

\section{SECOND DEGREES}

Sir, firstly we would like to compliment Pepper and Tabiat-Pour on publishing such a useful paper. ${ }^{1}$ We would like to point out a few omissions plus some additional sources of information to your readers.

In their first paragraph they say that whilst many books have been written on applying to medical school, none address the unique position of the dental graduate. Our Handbook for trainees in oral and maxillofacial surgery published in 1994 and the subsequent annual updates in 19951999 did cover this exact ground. We sent a book to every unit in the UK, plus most postgraduate libraries bought one. From 2000 onwards, the updates were published on the British Association of Oral and Maxillofacial Surgeons (BAOMS) website www.baoms.org.uk. Nabeela Ahmed wrote a similar document in 2002 for the British Association of Oral Medicine (which is also available on the BAOMS website). 